From the Department of Child Health, Medical School, University of Indonesia, Jakarta.

\title{
Levocardia With Situs Inversus Atria \\ (Case Report)
}

\author{
by \\ BAMBANG MADIYONO, IRAWATI PULUNGAN, P.M.C. \\ PELUPESSY and MAEMUNAH AFFANDI.
}

\begin{abstract}
Three cases of Levocardia and situs inversus atria were reported.

The clinical diagnosis of the first two cases were based on clinical signs and laboratory findings which were confirmed by Electrocardiography, Chest $X$ ray, heart catheterization and angiography.

The third case died before further investigations could be done.

Classification, management and prognosis were also discussed.
\end{abstract}

Received 28th. April 1975. 


\section{Introduction}

Levocardia with situs inversus atria is a condition in which the keart lies on the left hemithorax with ils base-apex axis pointing to the left and morphologically the right atrium lies on the left side of the heart.

In the majority of cases the position of the atria corresponds to that of the abdominal viscera, although there are odd cases where discrepancies between the sites of these structures occur (Sharer et al., 1967).

Although there was no similarity of the positional anomalies of the heart in classification and terminology (Rosenbaum et al, 1962; Harris et al., 1965; Campbell et al., 1966; Lev et al., 1969; Dela Cruz et al., 1971; De La Cruz et al., 1974; Liberthson et al., 1973; Anselmi et al., 1972), Liberthson's olassification based on the atrial situs is the best according to our opinion, because it is easier to know all the anomalies present, which make adequate correction possible. Final diagnosis can only be done with autopsy.

Prognosis of these patients is not good. Patients usually die before one year old due to unsatisfactory pulmonary blood flow (Keith et ail., 1967 and Wood, 1968). This paper reports three patients. One died of excessive pulmonary blood flow.

\section{Case Report}

Case I

$$
\text { F., a } 2 \text { - year - old boy who }
$$
was first seen at the outpatient climic of the Cardliac Centre Dr. Cipto Mangunkusumo General Hospital, Jakarta, on June 15, 1972, had a history of cyanosis from 1 month of age which increased with age. Cyarotic spells were first noted at $\mathbf{3}$ months of age, about $2-3$ times a month, which decreased later on. The boy could only take small quantities of food and milk since infancy. He had limited exercise tolerance, delayed growth and development.

Physical examination revealed a boy of approximately 2 years old with a body weight of $9 \mathrm{~kg}$., body Ilength $82 \mathrm{~cm}$., temperature of $37^{\circ} \mathrm{C}$, cyanosis on the lips, oral mucosa and nails.

Pulse was 120 per minute, regular, equal with normal volume. Respiration rate was 28 per minute, blood pressure on the arm was $90 / 55 \mathrm{~mm}$ $\mathrm{Hg}$, on the lower limb $100 / 60 \mathrm{~mm}$ Hg. JVP was not raised, hepato-jugular reflux was negative. Bulging of the left hemithorax with increased activity of the heart without enlargement was present. There was increased intensity of the first heart sound, the second heart sound was single. There was no murmur. Liver and spleen were not palpable; there was clubbing of the fingers and toes. 
The electrocardiogram revealed right ventricular hypertrophy with $P$ axis at about $+130^{\circ}$. (Fig. Ia). Chest X-ray revealed right aortic arch, slightly enlargement of the heart with upward apex, infiltrations at both lung fields, decreased vascular markings of the lungs. Abdominal X-ray with barium revealed inversion of the gaster and displacement of the colon. (Fig. Ib). Laboratory findings: normal urine and stool, the hemoglobin content ranged from $17-18$ gm $\%$, and the haematocrit was $50-52 \%$.

Catheterization and angiocardiography revealed atrial inversion with persistent left vena cava superior and inferior, functional single ventricle, right aortic arch and pulmonary arteries originating from the aorta. (Fig. Ic). Diagnosis was levocardia, situs inversus atria, single ventricle, pulmonary atresia with visceral heterotaxis.

\section{Case II}

E.J., a girl who first came to the outpatient clinic of the Cardiac Centre on February 8, 1971 with a history of cyanosis on crying since 7 months of age, which increased with age. (Fig IIa) Cyanotic spells were first detected 1 month before admission. The girl could only take small quantities of food and drinks since infancy. Sometimes after exercise she complains of headache and chest pain. Exercise tolerance was limited, the patient was easily tired. Cyanosis decreased later on. There is a slightly delayed growth and dever lopment. Physical examination revealed a girl of about 4 years old with a body weight of $12.5 \mathrm{~kg}$., body length of $92 \mathrm{~cm}$., temperature of $37^{\circ} \mathrm{C}$, cyanosis on the lips, oral mucosa and nails; respiration rate was 28 per minute, pulse was 136 per minute, regular, equal with normal volume. Blood pressure on the arm was $90 / 60 \mathrm{mmHg}$, on the lower limb $100 / 70 \mathrm{mmHg}$. JVP was not raised, hepatojugular reflux was negative. Increased activity of the heart without cardiac enlargement was present. There was a normal first heart sound, increased intensity of the single second heart sound; there was no murmur. Liver and spleen were not palpable. Clubbing of the fingers and toes was present. The electrocardiogram revealed a left ventricular hypertrophy with $\mathrm{P}$ axis of about $+180^{\circ}$. (Fg. Ilb).

Chest $\mathrm{X}$ ray revealed a normal heart size, right aortic arch and normal vascular markings of the lungs. (Fig. IIc).

Laboratory: normal urine and stool, the hemoglobin content ranged from $15.5-17 \mathrm{gm} \%$ and the hematocrit was $55 \%$.

Catheterization of the heart and angiocardiography revealed atrial inversion, left vena cava superior and inferior, single ventricle, right aortic arch, pulmonary atresia. The pul- 
monary arteries oniginated from the aorta descendens. (Fig. IId).

Diagnosis was levocardia, atriall inversion, single ventricle, right aortic arch and pulmonary atresia.

\section{Case III}

E., an eight-month-oll girl who was admitted on November 15, 1972 with a history of recurrent fever, cough and dyspnea for about 1 month before admission. Cyanosis appeared on crying since 1 month of age; cyanotic spells were never noted. There was slightly delayed growth and development with slightly limited exercise tolerance. Physical examination revealed a female infant of about 8 months old with a body weight of $6700 \mathrm{gm}$, body length of $67 \mathrm{~cm}$, temperature of $39^{\circ} \mathrm{C}$ and cyanosis and dyspnea. Pulse rate was 140 per minute, respiration rate was 48 per minute, blood pressure was $80 / 40$ mmHg. JVP was not raised with negative hepatojugular reflux. She had a symmetrical chest, increased activity of the heart, with enlargement of the heart to the left and right. There was a normal first heart sound with increased intensity and a normal split second heart sound. Pansystolic murmurs grade II/IV at the third left sternal border were detected. Lungs revealed an increased vesicular respiration; moist rales, at both lungs were heard. Liver was enlarged but the spleen was not palpable. Clubbing of the fingers and toes was present.
The electrocardiogram revealed a combined ventricular hypertrophy with $P$ axis of about $+90^{\circ}$.

Chest X-ray revealed enlargement of the heart to the left, increased vascular markings of the lungs with para and retrocardial infiltrates. Oesophagogram showed displacement of the gaster to the right. There was silhouette of a tissue at the right ani left part of the upper abdomen with configuration similar with the liver. (Fig. IIIa).

Laboratory findings: urine and stool were normal, the hemoglobin content ranged from $12-13 \mathrm{mg} \%$ : the hematocrit ranged from 45 $46.5 \%$ and the leucocyte count was 11.800 per $\mathrm{mm}^{3}$.

Diagnosis was levocardia with ventricular septal defect, visceral heterotaxis, bronchopneumonia and congestive heart failure.

\section{Discussion}

Levocardia with situs inversus atria is a rare congenital heart disease. In 15 years Liberthson et al. (1973) reported 30 cases of levocardia with heterotaxis among 3500 cases of congenital heart disease or $0.88 \%$ and among these there was 6 of levocardia with situs inversus atria or $0.17 \%$.

Usually malposition of the heart and other organs are easily recog. 
nized if situs visceroatrial and axis of the apex were known, whereas for certain cases it can only be proved by autopsy and pathologic findings. (Lev. 1954).

Liberthson et al. divided their 30 cases of levocardia with visceral heterotaxis into 3 groups based on cardiac lesions, degree of heterotaxis of the body viscera and abnormality of the spleen. The first group consists of patients with atrial situs solitus (morphologically right atrium lies on the right part of the heart and left atrium on the left part of the heart).

All of the patients show abnormal or agenesils of the spleen; other organs only suffer partial situs inversus or heterotaxis and several cases show venoatrial communication disorders. Condition of the great vessels is generally normal, atrial septum is intact; there is usually a Jesion on the left side of the heart e.g. coarctation of the aorta, aortic stenosis with mitral atresia.

The second group consists of patients with atrial situs inversus (morphologically right atrium lies on the lef $f_{t}$ side of the heart and left atrium on the left side).

The spleen usually is normal, there is complete situs inversus, right aortic arch, normal venoatrial communication and there is cardiac lesion such as ventricular septal defect, single ventricle with pulmonary atro- sia or stenosis. In all cases there were also found a transposition of the great vessels (D-ty'pe).

The third group consists of patients with indeterminate atria (atria not absolutely diagnosable). The majority of the patients in this group show partial or complete trans. position of the great vessels (Dtype). Usually there is also common atrium or large combined septal defect and in the majority of cases there is pulmonary atresia or stenosis. Part of this group show right aortic arch and the other part left aortic arch. In some patients inversion of the ventricles can be obser. ved.

According to radiological examination, electrocardiographic findings, catheterization and angiogra'phy of the heart, our first two cases could be included to the second group, whereas the third case, although it belongs to levocardia with visceral heterotaxis, can not be included in one of the Liberthson's groups because no complete examinations was done. Inversion of atrium is already suspected if on electrocardiographic examination there was inverted $P$ wave in lead I ( $P$ axis $90-140$ ) (Nadas, 1963; Liberthson et al., 1973), whereas the presence of the common ventricle is already imagined if there is a single second heart sound (Keith et al., 1967 and Wood, 1968). The existence of agenesis of the spleen is suspected if on abdo- 
minal $\mathrm{X}$ ray there is symmetric liver or blood examination shows a picture similar to post-splenectomy (Lukas et al., 1962).

The prognosis of patients with le. vocardia and visceral heterotaxis depends upon the existance of associated intracardiac anomalies which affect the pulmonary vascular resistance (Liberthson et al., 1973; Woor, 1968, Keith, 1967).

If at a young age pulmonary vascular resistance was normal but pu!monary blood flow was increased, there will be an excessive circulation in the lungs. This condition is usually the cause of death in the first. months. If the patient can reach 1 year of age usually improvement of the pulmonary blood flow occurs. Therefore early diagnosis is very important for correction of the pusmonary blood flow so that cyanosis is expected to decrease and the abi- lity of exercise can be improved. Banding of the pulmonary artery is the surgical treatment to improve very excessive pulmonary blood flow. whereas shunting operation is for patients with severe cyanotic spells caused by decreased pulmonary blood flow. The first and second case show decreased cyanosis and cyanotic spells in the last months, which are perhaps due to improvement of pulmonary blood flow, whereas the third case died afterwards due to an excessive pulmonary blood flow before reaching one year of age.

\section{Acknowledgement}

The authors are very grateful to A. Hanafiah M.D. of the Cardiac Centre and Soedarmo, M.D. and associates of the Department of Raciology Dr. Ciptomangunkusumo General Hospital for their friendly cooperation.

\section{REFERENCES}

1. ANSELM, G., MUNOZ, S., BLANCO, P., MACHADO, I. and DE LA CRUZ, M.V.: Systematization and clinical study of dextroversion, Mirror image dextrocardia and laevoveration. $\mathrm{Br}$. Heart J. 34 : 1083 (1972).

2. BUSH, J.A. EINGER, L.E.: Congenital absence of the spleen with congenital heart disease: Report of a case antemortem diagnosis on the basis of hematologic morphology. Pediatrics, $15: 93$ (1955).

3. CAMPBELL, M., REYNOLDS, G. : The significance of the direction of the $P$ wave in dextrocardia and isolated levocardia. Br. Heart J. $14: 481$ (1952).

4. CAMPBELL, M., FORGACS, P.: Levocardia with transposition of the abdominal viscera. Br. Heart J. $15: 401$ (1953).

5. CAMPBELL, M., DEUCHAR, D.C. : Dextrocardia and isolated levocardia II situs inversus and isolated dextrocardia. Br. Heart J. 28 : 472 (1966).

6. DE LA CRUZ, M.V., ANSELMI, G., MUNOZ - CASTELLANOS, L.: Systematization and embryological and anatomical study of mirror image dex- 
trocardlas, dextroversions and laevoversion, Br. Heart J. 33 : 841 (1971).

7. DE LA CRUZ, M.V., AMOEDO, M., RIVERA and ATTIE FAUSE. : Arterlo ventricular relations and their classification. Br. Heart J. 36 : 539 (1974).

8. HARRIS, T.R., RAINEY, R.L. : Ideal isolated levocardia. Am. Heart J. 70 : 440 (1965).

9. KEITH, J.D., ROWE, R.D., VLAD, P. : Heart disease in infancy and childhood. 2nd Ed. (Macmillan, New York, 1967).

10. LEV. M., LIBERTHSON, R.R., KIRK PATRICK, J.R., ECKNER, FAO, ARCILLLA, R.A., : Single (primitive) ventricle. Circulation 39 : 577 (1969),

11. LEV, M., ROWLATT, U.F.: The pathologic anatomy of mixed levocardia: A review of thirteen cases of atrial or ventricular inversion with or without corrected transposition. Am. J. Cardiol. 8 : 216 (1961).
12. LEV. M. : Pathologic diagnosis of positional variations in cardiac chambers in congenital heart disease. Lab. Invest. $3: 71$ (1954).

13. LIBERTHSON, R.R., HASTREITER, A.R., SINNA S.N., BHARATI, S., NO. VAC. G., LEV. M., : Levocadia with visceral heterotaxia isolated levocardia: Pathologic anatomy and its clinical implications. Am. Heart J. $85: 40$ (1973).

14. MOSS, A.J., and ADAMS, F.H.: Heart disease in infants, children and adolescents (Williams \& Wilkins, Baltimore 1968).

15. NADAS, S.A.: Pediatric cardiology, (Saunders, Philadelphia 1973).

16. ROSENBAUM, H.D., PELLEGRINO, E.O., TRECIOKAS L.J. Acyanotic lovocardia. Circulation 26 : 60 (1962). 


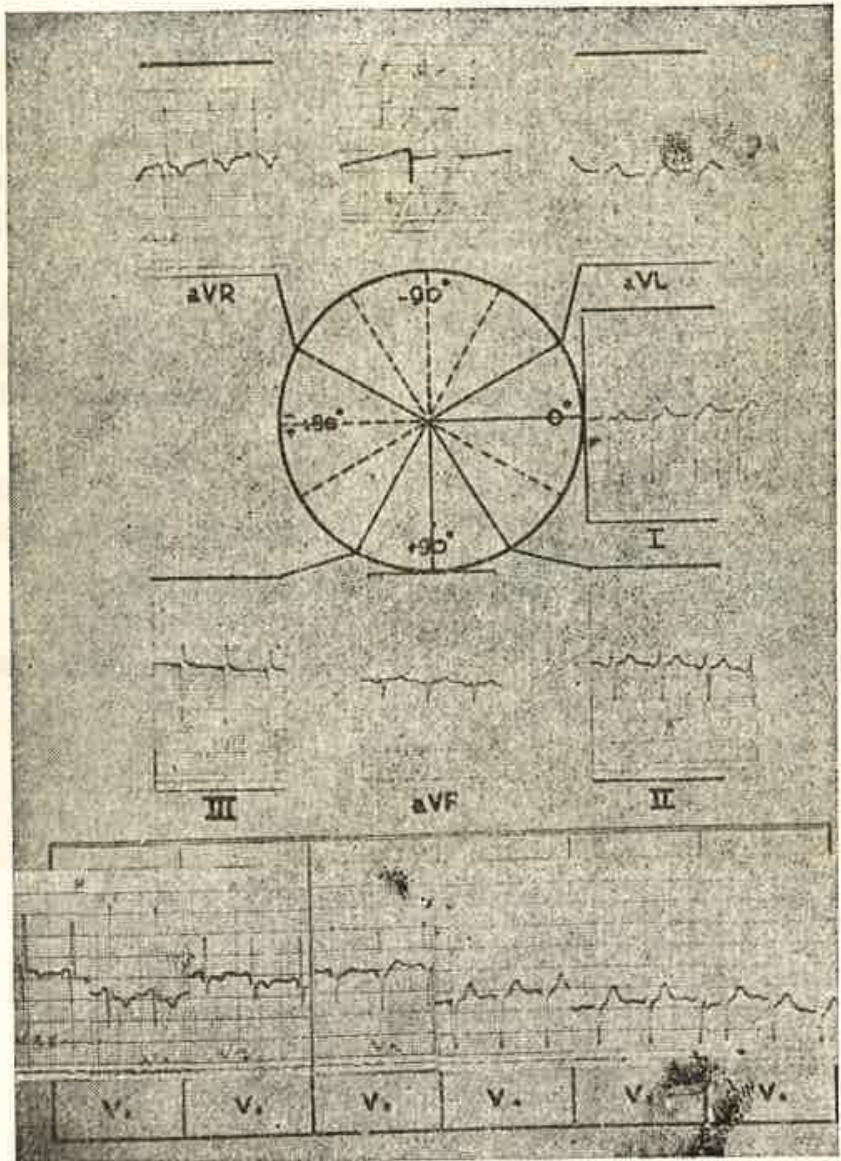

FIG. I a. 


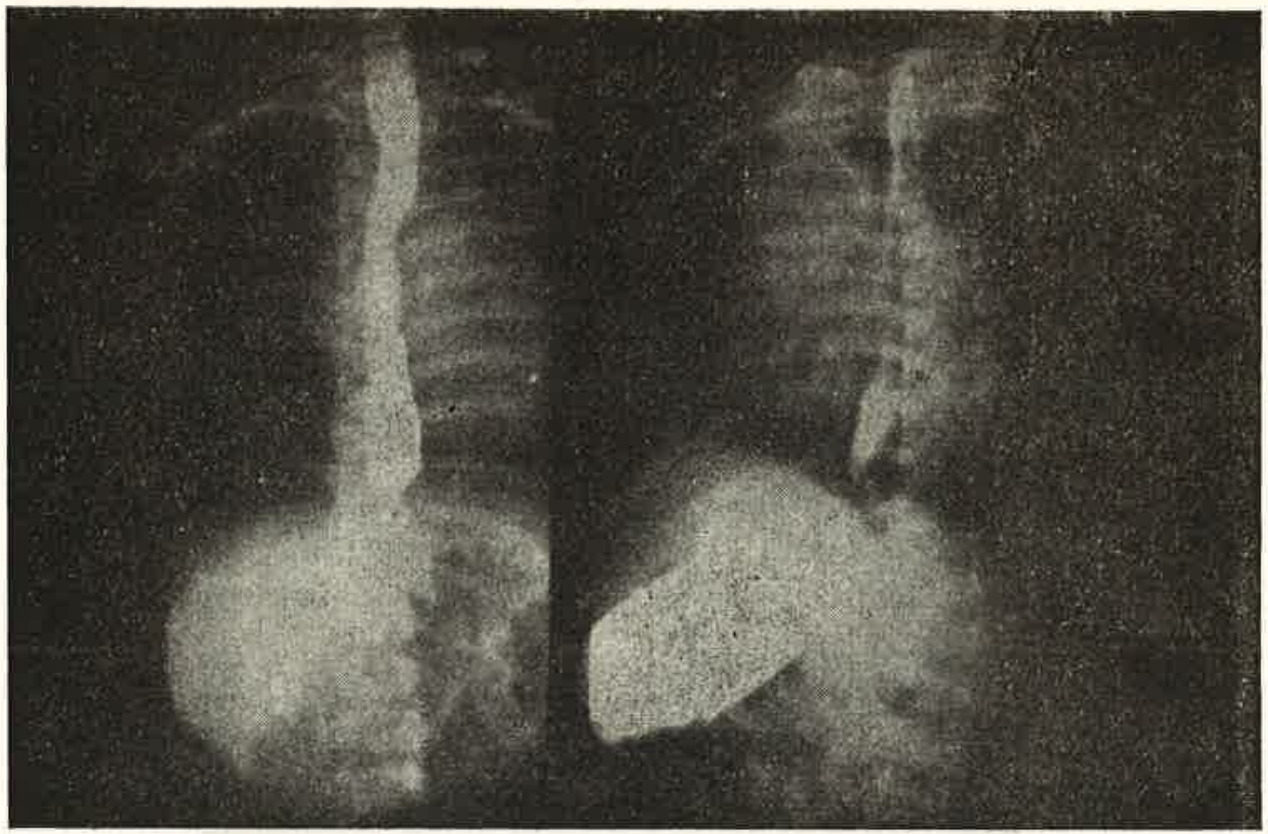

FIG. I b. 


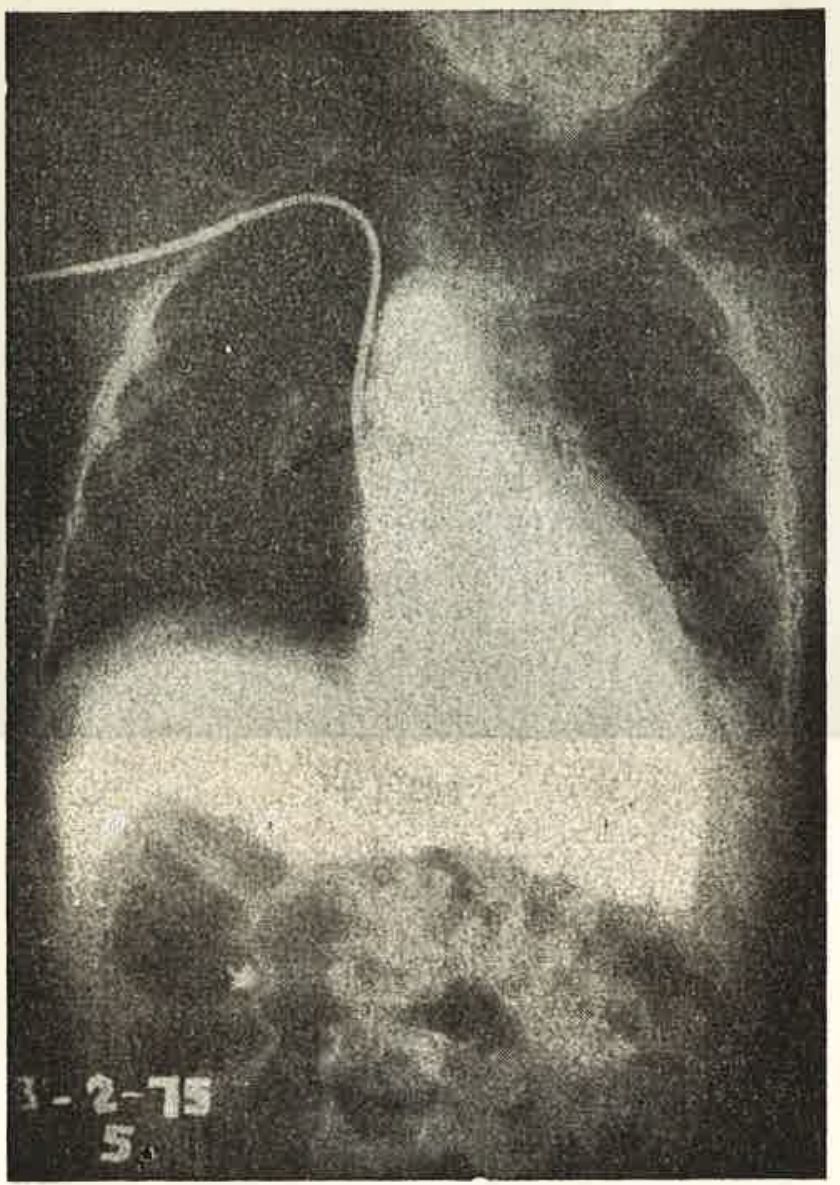

3

FIG. I c. 


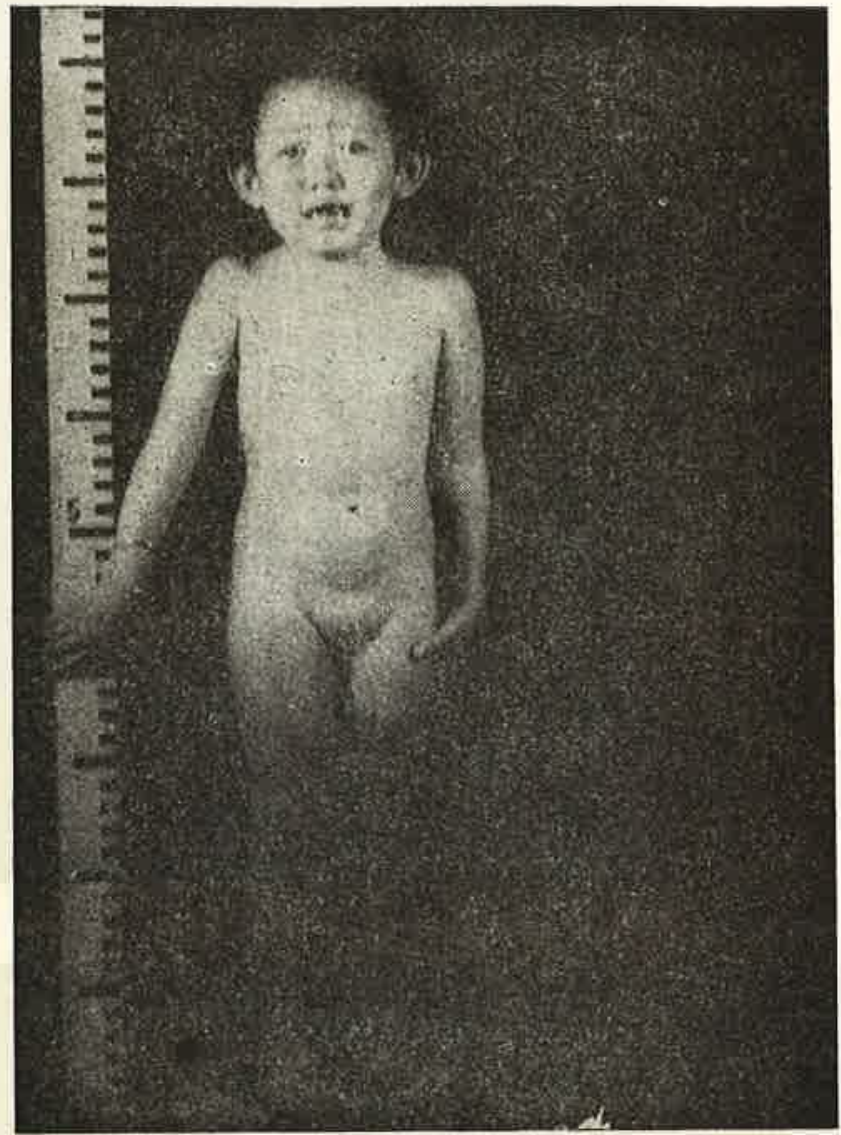

FIG. II a. 


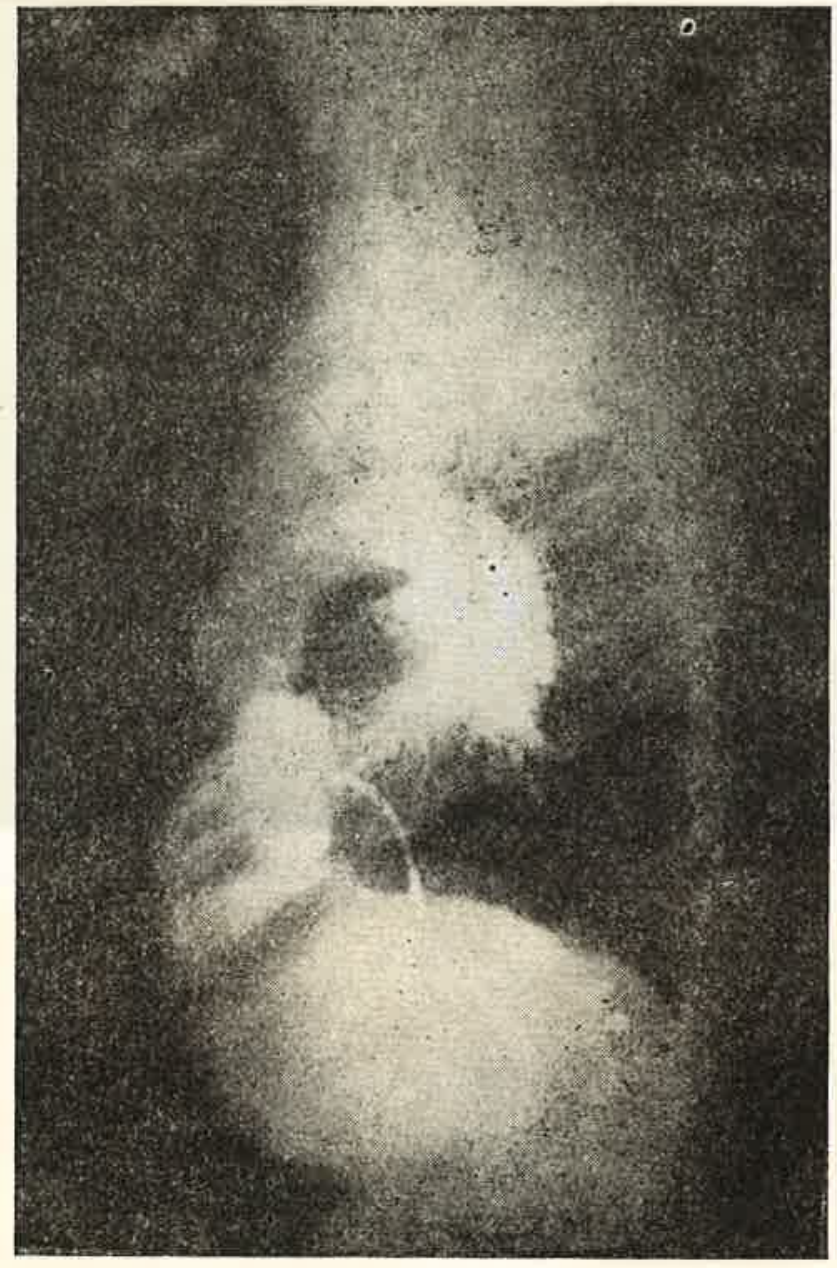

FIG. II d. 


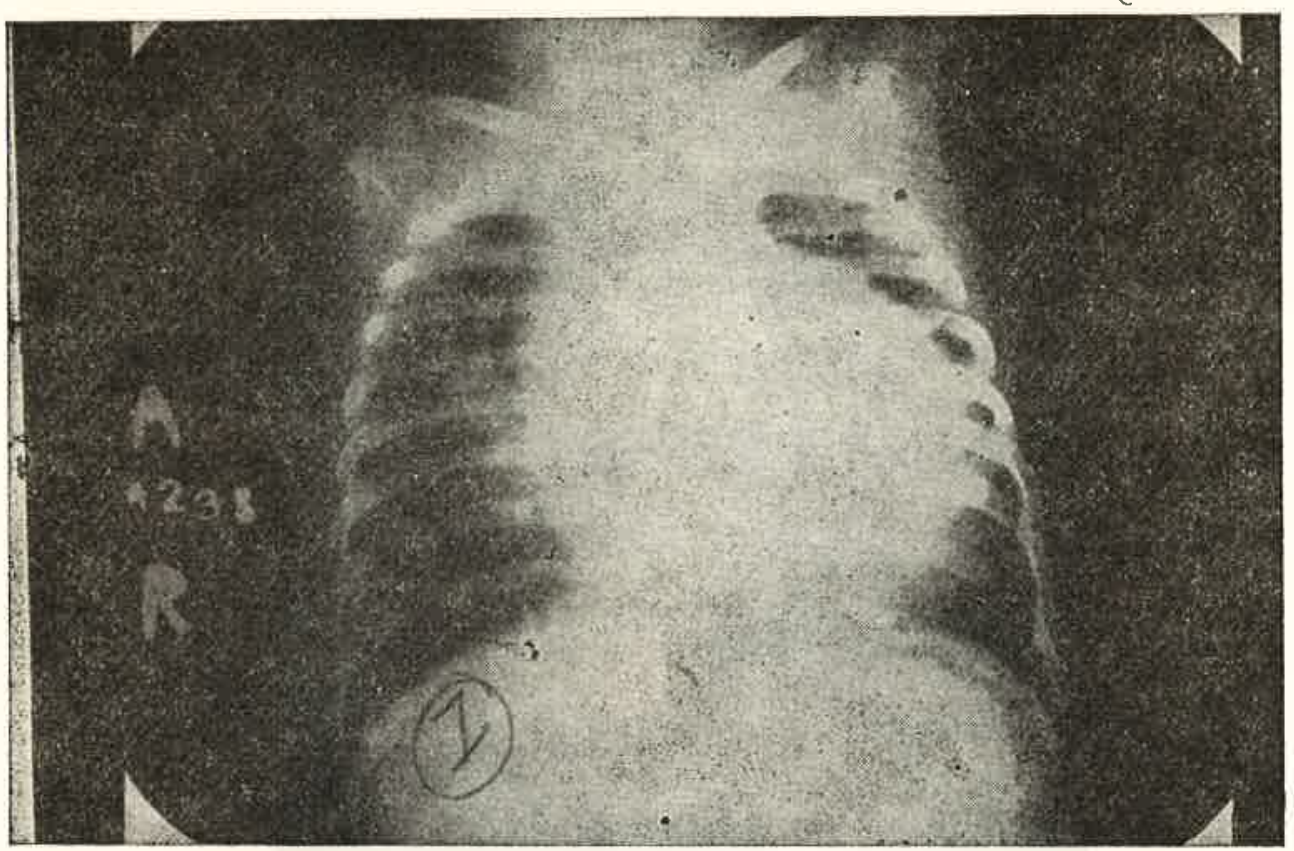

FIG. III a. 